\title{
The why and what of academic goals, their perceived value and relation to academic goal pursuit
}

\author{
Gail McMillan \\ Carleton University \\ Ryan C. Svoboda \\ Northwestern University
}

\author{
Kaitlyn M. Werner \\ University of Toronto \\ Marina Milyavskaya \\ Carleton University
}

\begin{abstract}
What predicts goal-relevant behaviours when students are confronted with motivational conflicts? Drawing on value-based models, self-determination theory, and the goal complex model, a comprehensive goal framework tested the assumption that what a student wishes to achieve depends on why goals are being pursued, and that these determine subjective task value, goal pursuit and self-regulated learning. A cross-sectional survey of college students $(n=366)$ found that autonomous motivation predicted goal pursuit and self-regulated learning. The relationship between autonomous motivation and the outcomes (e.g. goal pursuit and self-regulated learning) could be partially explained by higher attainment value for major, but not intrinsic and utility values. While mastery aims predicted goal pursuit and self-regulated learning, the strongest associations were observed when mastery aims were being pursued for autonomous motives. Attainment value mediated the relationship between the combined mastery-autonomous goal complex and the outcomes. Performance aims, more likely to be pursued for controlled motives, were generally nonadaptive. These findings support self-determination theory and value-based models.
\end{abstract}

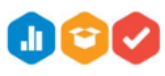

Pre-registration, data, analysis code, supplementary material: $\underline{\text { osf.io/a } 5 \mathrm{wfn} /}$

Keywords: self-determination theory, value-based choice, achievement aims, achievement goal complex, goal pursuit

THIS MANUSCRIPT IS UNDER REVIEW - IT HAS NOT BEEN PEER-REVIEWED AND IS SUBJECT TO CHANGE THROUGHOUT THE EDITORIAL PROCESS.

A common part of human experience is the pursuit of various goals, whether that is at work ("get a promotion"), in exercise ("cycle one day a week"), for health ("quit smoking"), or relationships ("spend more time with family"). The what and why of individuals' decisions to forego immediate, and sometimes detrimental, desires in favour of pursuing long-term goals is not fully understood. Why do students sometimes find they can employ self-regulatory strategies and study for a class test when they want to go out with friends, but other times they do not? This study aimed to examine the relationships between several motivational mechanisms and present an

Correspondence concerning this manuscript should be addressed to

Marina Milyavskaya, Department of Psychology, Carleton University, 1125

Colonel By Drive, Ottawa, ON, K1S 5B6, Canada.

Email: marina.milyavskaya@carleton.ca integrative framework for predicting goal pursuit and effective self-regulated learning for academic goals.

Self-regulated learning is the application of strategies to enhance active learning in the academic context and is comprised of several components. Selfregulated learners think about how best to learn and employ strategies (known as metacognitive strategies) to enhance learning, such as planning an appropriate amount of time to study, continuously assessing comprehension of material, and regulation (i.e. adjusting strategies for difficulty) (Vanderstoep, Pintrich, \& Fagerlin, 1996). Self-regulated learning is also defined by effort management, study strategies (e.g. processing information deeply by relating it to prior knowledge), persistence, and time management (Elliot, McGregor, \& Gable, 1999; Pintrich \& de Groot, 1990; Pintrich, Smith, Garcia, \& Mckeachie, 1993). 
Goal pursuit is the self-regulatory process where goaldirected actions are undertaken to enact plans and intentions that have been committed to (Gollwitzer, 1990, 1993). During this self-regulatory phase, individuals monitor and compare their current state to their desired end state (i.e. "am I making progress on this goal?") as part of a discrepancy-reducing feedback loop (Carver \& Scheier, 1998). Where there is a discrepancy, individuals attempt to reduce it by mobilising effort and engaging in goal-promoting behaviours (Achtziger \& Gollwitzer, 2008). Therefore, goal pursuit has been operationalised here as expected grade (e.g. desired end state), goal progress (e.g. monitoring the discrepancy), and effort. Self-regulated learning and each of these goal pursuit components are antecedents to goal attainment (Carver \& Scheier, 1998; de Bruijn-Smolders, Timmers, Gawke, Schoonman, \& Born, 2016; Fishbach, Eyal, \& Finkelstein, 2010; Harkin et al., 2016; Sheldon \& Elliot, 1999; Vasalampi, Nurmi, Jokisaari, \& SalmelaAro, 2012).

\section{The Importance of the 'What' and 'Why' in Goal Pursuit}

The 'why' of motivation, or the motivation for selecting and pursuing a goal, is a fundamental determinant of goal pursuit and attainment (Ryan \& Deci, 2000). According to self-determination theory, people pursue goals and perform behaviours for autonomous and controlled motives, which has implications for the self-regulation of behaviour (Ryan \& Deci, 2000). Autonomous motivation refers to motivation where a person truly wants to pursue the goal because the pursuit is inherently enjoyable (intrinsic motivation), the goal is congruent with one's self-concept (integrated motivation), or it is personally important (identified motivation). These goals are derived internally from one's own values and interests and so are pursued in a more self-determined fashion, with greater volition. In contrast, controlled goals are pursued because a person feels like they have to, due to either internal or external pressure. This includes pursuing goals to avoid feeling guilt or shame (introjected) or for approval or tangible rewards from others (extrinsic). Goals pursued for introjected or extrinsic motivation require the individual to be more controlled and less self-determined.

Compared to controlled goals, autonomous goals are more likely to be attained (Milyavskaya \& Inzlicht, 2017; Milyavskaya, Inzlicht, Hope, \& Koestner, 2015; Werner, Milyavskaya, Foxen-Craft, \& Koestner, 2016;
Werner, Milyavskaya, \& Koestner, 2018), lead to the greater use of self-regulated learning strategies (Vansteenkiste, Lens, \& Deci, 2006; Vansteenkiste et al., 2006; Vansteenkiste, Sierens, Soenens, Luyckx, \& Lens, 2009), and result in better achievement outcomes (Black \& Deci, 2000; Fortier, Vallerand, \& Guay, 1995; Guay, Ratelle, Roy, \& Litalien, 2010). The increased likelihood of attainment of autonomously motivated goals is partially due to increased effort and persistence during goal pursuit (Ratelle, Guay, Vallerand, Larose, \& Senécal, 2007; Sheldon \& Elliot, 1998; Vansteenkiste, Simons, Lens, Sheldon, \& Deci, 2004; Vasalampi et al., 2012).

There is less consistent evidence for the effect of controlled motivation on goal pursuit. Some studies have shown associations between controlled motivation and negative experiential outcomes, such as encountering more obstacles, temptations, and conflict during goal pursuit, as well as greater use of surface learning strategies (Brunet, Gunnell, Gaudreau, \& Sabiston, 2015; Donche, De Maeyer, Coertjens, Van Daal, \& Van Petegem, 2013; Milyavskaya et al., 2015). Meanwhile, many studies have found no relationship between controlled motivation and goal progress (Koestner, Lekes, Powers, \& Chicoine, 2002; Koestner, Otis, Powers, Pelletier, \& Gagnon, 2008; Werner et al., 2018).

In addition to the reasons that goals are pursued (the why), consideration must also be given to the direction of the behaviour, that is what the individual wishes to achieve (Dweck, 1986; Maehr \& Nicholls, 1980; Nicholls, 1984). Achievement aims refer to the aim of one's achievement behaviour in a competence-relevant situation (Elliot, 1999). Achievement aims are either directed toward performance (e.g. a demonstration of competence to outperform others) or mastery (e.g. a demonstration of development of knowledge or a skill). Mastery aims are generally adaptive as they are associated with self-regulated learning strategies, persistence, and effort but they are not consistently related to achievement (Grant \& Dweck, 2003; Harackiewicz, Durik, Barron, Linnenbrink-Garcia, \& Tauer, 2008; Hulleman, Schrager, Bodmann, \& Harackiewicz, 2010; Liem, Lau, \& Nie, 2008; Vrugt \& Oort, 2008). Performance aims have a positive relationship with achievement when framed as approach goals (i.e. directing effort toward gaining a desirable outcome) (Dweck \& Leggett, 1988; Hulleman et al., 2010; Rawsthorne \& Elliot, 1999). Conversely, there are negative or null relationships between achievement and performance aims when they are framed as avoidance goals (i.e. directing effort 
towards avoiding an undesirable outcome) (Harackiewicz, Barron, Pintrich, Elliot, \& Thrash, 2002; Hulleman et al., 2010; Stoeber, Uphill, \& Hotham, 2009). To prevent confounding of multiple goal constructs, when using the labels mastery aims and performance aims throughout this paper, we will be referring to approach goals1.

\section{Goal Complexes in Goal Pursuit}

There is evidence that both achievement aims (mastery, performance) and motivation (autonomous, controlled) have unique effects on achievement outcomes (Benita, Roth, \& Deci, 2014; Sommet \& Elliot, 2017). However, there is also evidence that motivation is an antecedent to achievement aims, that motivation is fundamental in determining outcomes, and that the effects of aims are negligible or moderated by motivation (Ciani, Sheldon, Hilpert, \& Easter, 2011; Gaudreau, 2012; Michou, Vansteenkiste, Mouratidis, \& Lens, 2014; Werner et al., 2018). The goal complex model addresses this by assuming that the same achievement aim may have different effects if being pursued for different underlying motives (Elliot, 2005; Elliot \& Thrash, 2001; Urdan \& Mestas, 2006). The goal complex model thus combines achievement aims and motivation into four possible "goal complexes". For example, a student may want to outperform other students (performance aim) because they find the challenge enjoyable (autonomous motive). Conversely, this goal of outperforming other students may have drastically different effects on experience, learning, and achievement when pursued to gain approval from teachers (controlled motive).

Consistent with the goal complex model, the performance-autonomous complex was more strongly related to the mastery-autonomous complex than the performance-controlled complex (Senko \& Tropiano, 2016). The performance-autonomous complex predicted self-efficacy, interest, and self-regulated learning, similar to mastery aims (Senko \& Tropiano, 2016; Sommet \& Elliot, 2017). The performancecontrolled complex was unrelated to mastery aims, correlated strongly with performance-avoidance aims, and predicted help-avoidance and self-handicapping (Senko \& Tropiano, 2016). Furthermore, masteryautonomous goal complexes uniquely predicted

\footnotetext{
1 The approach and avoidance distinction is being applied to mastery and performance aims here but not to autonomous and controlled motivation. The differential effects of defining achievement aims with either an approach or avoidance orientation has been established (e.g . Harackiewicz, et al., 2002; Hulleman, et
}

experiential and self-regulated learning outcomes over and above the effects of mastery aims and autonomous motivation when all were entered into a model (Sommet \& Elliot, 2017).

\section{Subjective Value in Academic Goal Pursuit}

During goal pursuit, the process of engaging in goalconsistent behaviours or tempting alternatives can depend on the subjective value of each option. Subjective value is one of the most proximal determinants to achievement behaviour during academic goal pursuit (Berkman, Hutcherson, Livingston, Kahn, \& Inzlicht, 2017; Eccles, Wigfield, Adler, Goff, \& Kaczala, 1983; Feather, 1982; Wigfield $\&$ Eccles, 1992). Subjective value is determined when there is the integration of a variety of salient value inputs (e.g. social norms, attributes of the choices, identity), which determine the rewards and costs of a behaviour (Berkman et al., 2017; Milyavskaya \& Inzlicht, 2018).

Subjective task values specific to academic pursuits have been identified, namely intrinsic value, attainment value, and utility value (Eccles et al., 1983; Wigfield \& Eccles, 1992). Interest value is the amount of inherent enjoyment or interest that the task provides (Eccles et al., 1983). Utility value is the usefulness of the activity to the individual's important life goals, including how instrumental the task is for future goals (e.g. career goals), for social endeavors, and for navigating daily life (Eccles et al., 1983). Attainment value is defined as the value of the task in affirming one's identity or personal values (Eccles \& Wigfield, 2002). There is seemingly some overlap between the constructs of autonomous motivation and subjective task values. Yet, interest, attainment, and utility values are defined as the perception or judgement of the value of a task (Eccles \& Wigfield, 2002), while autonomous motivation represents the degree to which regulation of behaviour is volitional (Deci \& Ryan, 2000).

The accumulation of task values dictates the overall subjective value or valence of an academic task (Berkman et al., 2017; Eccles et al., 1983; Milyavskaya \& Inzlicht, 2018; Wigfield \& Eccles, 1992). Interest, utility, and attainment values have demonstrated associations with persistence, effort, achievement, and progression to further training and careers in the subject

al., 2010). Meanwhile, there is scarce evidence that an interaction between approach-avoidance orientations and autonomous and controlled motivation contributes to the variance in goal pursuit (e.g. see Werner et al., 2018). 
area (Gaspard et al., 2018; Hagemeier \& Murawski, 2014; Lauermann, Tsai, \& Eccles, 2017; Perez, Cromley, \& Kaplan, 2014; Perez et al., 2019; Robinson et al., 2019; Simons, Dewitte, \& Lens, 2003; Tulis \& Fulmer, 2013; Wang, Degol, \& Ye, 2015; Wu \& Fan, 2017).

Shifts in the subjective value of behaviour choices may be driven by fluctuations in motivation, which alters the experience of goal pursuit (Berkman et al., 2017; Milyavskaya \& Inzlicht, 2018). Activities that are more interesting, enjoyable, and aligned to personal values are more inherently rewarding in the moment (Peetz, Milyavskaya, \& Davydenko, 2020; Ryan \& Deci, 2008). By comparison, goals pursued for controlled motives hold the promise of a distal reward (e.g. financial incentive, approval from others), but are less likely to be rewarding in the moment (Milyavskaya \& Inzlicht, 2018). Pursuing autonomous goals feels more automatic and effortless than pursuing controlled goals (Milyavskaya, Galla, Inzlicht, \& Duckworth, 2018; Milyavskaya et al., 2015; Werner et al., 2016). Autonomous academic goals are, therefore, likely to increase the interest, attainment, and utility values of achievement behaviours. Meanwhile, there is evidence of a positive relationship between subjective task values and mastery aims and, to a lesser degree, performance aims (Liem et al., 2008; Plante, O'Keefe, \& Théorêt, 2013), but this has rarely been examined.

\section{Current Study}

The present research aimed to extend previous research by presenting an integrative framework to account for the 'what' and 'why' of academic goals, and their perceived value. A better understanding of the relationships between these motivational constructs will further develop motivational theory of goal pursuit. In addition, ascertaining the strength of associations between underlying psychological processes which affect the valuation process can guide the design of learning environments that enhance subjective values and, in turn, achievement.

To accomplish this, a series of analyses were undertaken. First, the independent contribution of autonomous and controlled motivation to goal pursuit and self-regulated learning was assessed. Then, the function of intrinsic value, attainment value, and utility value in mediating the relationships between motivation and goal pursuit and self-regulated learning was evaluated. The contribution of mastery and performance aims, and goal complexes to goal pursuit and self-regulated learning was assessed. Finally, bridging these theoretical approaches to provide a comprehensive framework, the mediation of subjective task values in the relationship between goal complexes and the outcomes was examined.

Based on theory and extant literature reviewed here, we proposed several hypotheses (pre-registered at https://osf.io/a5wfn/). It was anticipated that autonomous motivation would positively predict the subjective values of intrinsic value (hypothesis 1a), attainment value (hypothesis $1 \mathrm{~b}$ ), and utility value (hypothesis 1c), as well as goal pursuit (hypothesis 1d) and self-regulated learning (hypothesis 1e). Intrinsic value, attainment value, and utility value were expected to positively predict the outcomes (hypothesis 2a-c respectively) and there would be a mediation relationship between autonomous motivation, subjective value, and the two outcomes (hypotheses $2 \mathrm{~d}$ $\& 2 \mathrm{e}$ respectively). It was expected that mastery aims would positively predict goal pursuit (hypothesis 3a) and self-regulated learning (hypothesis $3 \mathrm{~b}$ ) while performance goals would be related to goal pursuit only (hypothesis 3c). Autonomous-mastery and autonomous-performance complexes were expected to positively predict goal pursuit (hypotheses $4 \mathrm{a} \& 4 \mathrm{~b}$ ) and self-regulated learning (hypotheses $4 c \& 4 d$ ), while controlled motivation complexes would not. Finally, we investigated whether intrinsic value, attainment value, and utility value would mediate the relationship between autonomous goal complexes and the outcomes; this was pre-registered as an exploratory question (EQ1), although based on hypotheses 4 it could reasonable be expected that the relationship between autonomous complexes and the two outcomes would be mediated by intrinsic (hypotheses $5 \mathrm{a} \& 5 \mathrm{~b}$ ), attainment (hypotheses 5c \& 5d), and utility values (hypotheses 5e \& 5f).

\section{Method}

\section{Participants and Procedure}

We aimed to recruit a minimum of 300 participants, which was the required sample size to detect a small to medium effect size in a regression with ten predictors at $80 \%$ power ascertained using $\mathrm{G}^{*}$ power (Faul, Erdfelder, Buchner, \& Lang, 2009). A total of 456 undergraduate psychology students were recruited from subject pool in the Department of Psychology at Carleton University. After removing participants who failed pre-determined exclusion criteria and attention checks ( $n=80$ spent less than 8 minutes on the survey; $n=8$ failed 2 of 3 attention checks; $n=3$ did not consent 
to participate according to consent form), this left 366 participants. The participants were predominately female $(76 \%)$ and were on average 23 years old $(M$ age $=$ 22.91; SDage $=4.95)$. The participants completed an online cross-sectional survey, which included measures of achievement aims, motivation for goal pursuit, goal complexes, subjective value for major (psychology), goal pursuit, self-regulated learning, and demographic information.

\section{Measures}

Motivation for Goal Pursuit. Participants were asked to rate their motivation for pursuing their academic goal. Six items measuring autonomous and controlled motivation, as adapted from previous research (Michou et al., 2014) and used previously (Sommet \& Elliot, 2017), were prefixed with "In my psychology class, I pursue goals because...". One item each measured intrinsic motivation (e.g. "I find them highly stimulating and challenging") and identified motivation (e.g. "I find them personally valuable goals") which were averaged together to create the autonomous motivation composite. Split-half internal consistency (Spearman-Brown corrected) for the autonomous motivation composite was $r \mathrm{sB}=.64$, which is fair (Nunnelly \& Bernstein, 1994). Two items measured introjected motivation (e.g. "I would feel bad, guilty, or anxious if I didn't do it", "I can only be proud of myself if I do so.") and two items measured external motivation ("I have to comply with the demands of others such as parents, friends, and teachers", "others will reward me only if I achieve these goals"). These four items had fair internal reliability (Cronbach's $\alpha=66$ ). Motivation for goal pursuit was rated on a Likert scale ranging from 1 (strongly disagree) to 5 (strongly agree).

Achievement Aims. As with previous research (Michou et al., 2014; Sommet \& Elliot, 2017), achievement aims were measured with four items from the revised Achievement Goal Questionnaire (Elliot \& Murayama, 2008), two of which measured mastery goals and had poor internal consistency (split-half reliability $r \mathrm{sB}=.53$ ) and two of which assessed performance goals and had fair internal consistency (split-half reliability $r \mathrm{sB}=.64$ ). Participants rated the extent to which their achievement aims were oriented toward mastery ("My aim is to completely master the material presented in my classes", "My goal is to learn as much as possible") and performance (e.g. "My goal is to perform better than the other students", "My aim is to perform well relative to other students"). A composite for mastery and performance goals was created by averaging the items for each construct, respectively. Responses were rated on a Likert scale ranging from 1 (strongly disagree) to 7 (strongly agree).

Goal Complexes. In order to assess goal complexes, we followed the procedure of Somett and Elliot (2017). Participants rated the extent to which they were pursuing different achievement aims (mastery, performance) together with the underlying motivation (autonomous, controlled). This resulted in twenty-four items representing four subscales: mastery-autonomous (4-items; e.g., "My goal is to learn as much as possible because I find this a highly stimulating and challenging goal"), performance-autonomous (4items; e.g., "My goal is to perform better than the other students because I find this a highly stimulating and challenging goal"), masterycontrolled (8-items; "My aim is to completely master the material presented in my classes because I can only be proud of myself if I do so"), and performance-controlled (8-items; "My aim is to perform well relative to other students because I would feel bad, guilty, or anxious if I didn't do it"). All subscales demonstrated good reliability, ranging between .86-.92. Each item was rated on a Likert scale ranging from 1 (strongly disagree) to 7 (strongly agree).

Subjective Value for Major. Subjective value was indexed by three components, namely attainment value, utility value, and intrinsic value. These items were adapted from previous work (Eccles, O’Neill, \& Wigfield, 2005; Eccles \& Wigfield, 2002).

Attainment Value. Participants rated how important attainment in their major was on a Likert scale ranging from 1 (not important) to 7 (very important) with two items (e.g. "I feel that, to me, being good at psychology is..." and "How important is it to you to get good grades in psychology?"; with poor split-half reliability $r \mathrm{SB}=.56)$.

Utility Value. Six items were used to measure utility value (Cronbach's $\alpha=.86$ ). Five of these items measured how useful psychology is in daily life (e.g. "I can apply what we learned in psychology to real life") and to future employment (e.g. "It is important to understand psychology to get a good job") on a Likert scale from 1 (strongly disagree) to 7 (strongly agree). One utility value item about the general utility of the 
psychology class (e.g. "In general, how useful is what you learned in the psychology class?") was measured on a Likert scale ranging from 1 (not at all useful) and 7 (very useful).

Intrinsic Value. Four items were used to assess how interesting participants found their major (e.g. "I like to read about psychology topics"; "To be honest, I just don't find psychology interesting"- reverse coded). Responses were made on a Likert scale ranging from 1 (strongly disagree) to 7 (strongly agree). Internal consistency was excellent (Cronbach's $\alpha=.87$ ).

Goal Pursuit. Goal pursuit was conceptualized as a latent variable comprised of three components: goal progress, effort, and expected grade2. Participants rated their goal progress with three items (e.g. "I have made a lot of progress toward these goals in my psychology class"; $\alpha=.86$ ). Effort ("I have tried really hard to achieve my goals in my psychology class") was assessed using one item. Each of the goal progress and effort items, which have been used in previous research to index goal pursuit (Milyavskaya \& Inzlicht, 2017; Werner et al., 2016), were rated on a Likert scale ranging from 1 (strongly disagree) to 7 (strongly agree). Participants provided the expected grade for their major by selecting a letter grade on a 12-point scale (e.g. A+, A-, etc.) where higher values indicate higher grades.

Self-Regulated Learning. Self-regulated learning was operationalized as a latent variable comprised of five components, namely, self-regulation, deep study strategies, surface study strategies, persistence, and time management. All self-regulated learning items were rated on a 7-point Likert scale ranging from 1 (strongly disagree) to 7 (strongly agree).

Self-regulation. Adapted from the Motivated Strategies for Learning Questionnaire (Pintrich \& de Groot, 1990; Pintrich et al., 1993), we conceptualized self-regulation using the metacognitive learning strategies and effort management subscales (12 items total). Participants rated the extent to which they engage in metacognitive learning strategies (8-items), such as planning (e.g. "Before I begin studying I think about the things I will need to do to learn"), skimming (e.g. "I often find that I have been reading for class but don't know what it is all about"), and comprehension monitoring (e.g. "When I'm reading I stop once in a while and go over what I have read"). Effort

\footnotetext{
2 Within the pre-registration, we operationalized goal pursuit as being measured by goal progress, effort, persistence, obstacles, and expected grade. The addition of "persistence" to the goal pursuit construct within the pre-registration was an oversight and it was not measured as part of goal pursuit but as part of the self-regulated learning construct. This can be seen in the study materials on osf
}

management (e.g. "Even when study materials are dull and uninteresting, I keep working until I finish") was assessed with four items. All 12 items were averaged to obtain a measure of self-regulation, $\alpha=.81$ ).

Study strategies. The construct of study strategies was measured with a ten-item scale as used in achievement goal research previously (Elliot et al., 1999). Two five-item subscales assessed surface processing (e.g. "When I study for an exam in this course, I try to memorize as many facts as I can", "I try to memorize everything that I think will be on the exam") or deep processing (e.g. "I treat the course material as a starting point and try to develop my own ideas about it", "When I read or hear a theoretical point in this course, I think about possible alternatives"). Reliability for each the deep processing subscale (Cronbach's $\alpha=.74$ ) and surface processing (Cronbach's $\alpha=.82$ ) subscale was good. These were included as separate indices within the latent variable of Self-regulated Learning.

Time management. Participants rated their time management strategies such as planning and managing time (e.g. "I make good use of my study time for this course", "I find it hard to stick to a study schedule") using the eight-item time management subscale (Cronbach's $\alpha=.75$ ) of the Motivated Strategies for Learning Questionnaire (Pintrich \& de Groot, 1990; Pintrich et al., 1993).

Persistence. Persistence was assessed with three items (e.g. "When something that I am studying in my major classes gets difficult, I spend extra time and effort trying to understand it.") which have been used in previous achievement goals research (Elliot et al., 1999). Reliability was excellent (Cronbach's $\alpha=.85$ ).

Parents' Education Level. Parents' education level was calculated from one item which assessed mothers' education level and one item that assessed fathers' education level. Participants rated both mothers' and fathers' education level on a six-point scale where 1=elementary school, 2=high school, 3=CEGEP, 4=College Diploma, 5=Undergraduate university degree, $6=$ Masters, $\mathrm{PhD}$, or professional degree. The items were combined in an average to produce one continuous item of parents' education level.

(https://osf.io/b69zy/). Additionally, the small correlations between obstacles and the other goal pursuit constructs, and further consideration of the theoretical relevance of obstacles to goal pursuit, led us to conclude that "obstacles" was a distinct construct. Therefore, it was dropped form the goal pursuit construct and not included in analyses. 


\section{Analysis}

Means and standard deviations were calculated for each variable using composite scores. Pearsons' correlations were calculated for all latent and observed variables. The data were further analysed using structural equation modelling (SEM) to evaluate the relationships between motivation, achievement aims, subjective values, goal complexes, goal pursuit and self-regulated learning. Controlled motivation, interest value, utility value, mastery-autonomous complex, mastery-controlled complex, performance-autonomous complex, performance-controlled complex, goal pursuit, and self-regulated learning were treated as latent constructs. Autonomous motivation, attainment value, mastery aims and performance aims were treated as observed variables as these all had two indicators (Hoyle, 1995). The latent constructs of controlled motivation, interest value, utility value and each of the goal complexes were defined by their corresponding observed scale items. Goal pursuit was produced by three observed variables: goal progress, expected grade, and effort. Self-regulated learning was constructed from five observed variables: selfregulation, surface study strategies, deep learning strategies, time management and persistence. The lavaan package v0.6-6 (Rosseel, 2012) was used within R statistical software v3.6.2 (R Core Team, 2019) to conduct SEM analyses. Model parameter estimates were calculated using maximum likelihood estimation. Parents' education was entered as a covariate. The fully standardised solution is reported. The full output of all analyses, including the measurement portion of the models, can be found on OSF: https://osf.io/chpf6/.

Global model fit was assessed by several fit indices. The Chi-square goodness-of-fit statistic is reported and good model fit is indicated when the Chi-square test statistic is non-significant ( $p>.05$ ) (Barrett, 2007). However, the Chi-square statistic is sensitive to sample size and nearly always reaches significance with large sample sizes (Bentler \& Bonett, 1980). Therefore it is recommended that a combination of the Chi-square statistic, absolute fit and incremental fit indices are provided (Hoyle, 1995). The Comparative Fit Index (CFI) is reported where a cut-off value of $\geq .95$ indicates acceptable fit ( $\mathrm{Hu} \&$ Bentler, 1999). The root means square error of approximation (RMSEA) and 90\% confidence intervals are reported where values $\leq .05$ indicate good fit and values between .05 and .08 are considered fair fit (Browne \& Cudeck, 1992, 1993). The standardised root mean residual (SRMR) is provided where values $\leq .08$ are indicative of good fit (Hu \& Bentler, 1999).

\section{Results}

\section{Preliminary Results}

The means and standard deviations of all study variables are presented in Table 1. Pearson's correlations were conducted between all study variables and are presented in Table 2 .

There are some correlations presented in Table 2 that should be highlighted. The mastery-controlled and performance-controlled complexes were very highly correlated with each other. Controlled motivation was also very highly related to the mastery-controlled and performance-controlled complexes, while autonomous motivation is very highly correlated with the masteryautonomous complex. In addition, the subjective task values are moderately to highly correlated with one another.

\section{Motivation, Goal Pursuit, and Self-Regulated Learning}

We used structural equation modelling (SEM) to assess the relationship between autonomous and controlled motivation, goal pursuit, and self-regulated learning. Fit indices indicated that the model fit was adequate, $\mathrm{X}_{2}(65)=125.32, p<.001 ;$ RMSEA $=.050$ $(90 \%$ CI $[.037, .064]) ;$ CFI $=.95 ;$ SRMR $=.071$ (Tabachnick \& Fidell, 2007). The model explained $20 \%$ of the variance of goal pursuit and $23 \%$ of the variance of self-regulated learning. As presented in Figure 1, there was a positive relationship between autonomous motivation and both goal pursuit and selfregulated learning, consistent with our hypotheses. This indicated that as autonomous motivation increased, goal pursuit and self-regulated learning strategies increased. In contrast, there was a no relationship between controlled motivation and selfregulated learning and goal pursuit.

\section{Motivation, Subjective Values, Goal Pursuit, and Self- Regulated Learning}

As presented in Figure 2, a mediation model was conducted using SEM to examine whether motivation for goal pursuit was a source of subjective values, which, in turn, were expected to predict goal pursuit and self-regulated learning. 
Table 1.

Descriptive statistics of composites of variables

\begin{tabular}{|c|c|c|c|}
\hline Variable & Scale range & Mean & $S D$ \\
\hline \multicolumn{4}{|l|}{ Motivation } \\
\hline Autonomous & $1-5$ & 3.99 & 0.84 \\
\hline Controlled & $1-5$ & 2.90 & 0.68 \\
\hline \multicolumn{4}{|l|}{ Aims } \\
\hline Performance & $1-7$ & 5.12 & 1.30 \\
\hline Mastery & $1-7$ & 5.80 & 1.17 \\
\hline \multicolumn{4}{|l|}{ Subjective Task Values } \\
\hline Attainment & $1-7$ & 5.77 & 1.08 \\
\hline Interest & $1-7$ & 5.79 & 1.10 \\
\hline Utility & $1-7$ & 5.49 & 1.05 \\
\hline \multicolumn{4}{|l|}{ Goal pursuit } \\
\hline Goal progress & $1-7$ & 5.00 & 1.15 \\
\hline Effort & $1-7$ & 5.45 & 1.19 \\
\hline Expected grade & $1-12$ & 9.02 & 1.65 \\
\hline \multicolumn{4}{|l|}{ Self-regulated learning } \\
\hline Deep processing & $1-7$ & 4.80 & 0.95 \\
\hline Surface processing & $1-7$ & 2.68 & 1.00 \\
\hline Self-regulation & $1-7$ & 4.97 & 0.79 \\
\hline Persistence & $1-7$ & 5.69 & 0.93 \\
\hline Time management & $1-7$ & 5.15 & 0.85 \\
\hline \multicolumn{4}{|l|}{ Goal complexes } \\
\hline Mastery-autonomous & $1-7$ & 5.42 & 1.25 \\
\hline Performance-autonomous & $1-7$ & 4.39 & 1.34 \\
\hline Mastery-controlled & $1-7$ & 4.93 & 1.42 \\
\hline Performance-controlled & $1-7$ & 4.20 & 1.49 \\
\hline \multicolumn{4}{|l|}{ Covariate } \\
\hline Parents' education level & $1-6$ & 3.96 & 1.33 \\
\hline
\end{tabular}

Note: Means and standard deviations were calculated from the composite scores of the scales. For parents' education, levels of education were coded as follows: 1=elementary school, 2=high school, 3=CEGEP, 4=College Diploma, 5=Undergraduate university degree, $6=$ Masters, $\mathrm{PhD}$, or professional degree. 
Table 2. Pearson's correlations of all latent and observed variables

1. Autonomous motivation

2. Controlled motivation

3. Goal progress

4. Expected grade

\section{Effort}

6. Self-regulation

7. Deep studying

8. Surface studying

9. time management

10. Persistence

11. Interest value

12. Attainment value

13. Utility Value

14. Mastery aims

15. Performance aims

16. MA complex

17. MC complex

18. PA complex

19. PC complex

20. Goal pursuit

21. Self-regulated learning
2

.02

$.26 * * * \quad-.07$

$.09 \quad-.05 \quad .28 * * *$

$.26 * * * \quad-.06 \quad .35 * * * \quad .22 * \quad-$

$\begin{array}{rllll}.40 * * * & -.19 * * & .51 * * * & .32 * * * & .40 * * *\end{array}$

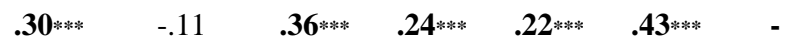

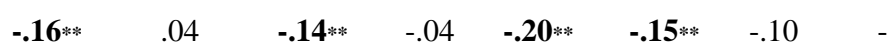

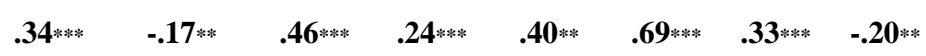

$.32 * * * \quad-.18 * *$

$.49 * * * \quad .12 *$

$.39 * * * * 01$

. $\mathbf{4 8} * * * * \quad .10$

$.57 * * * \quad .01$

$.29 * * * \quad .41 * * *$

$.77 * * * \quad .03$

$-.03 \quad .97 * *$

$.42 * * * \quad .27 * * *$

$-.03 \quad .90 * * *$

$.40 * * * \quad-.11$

$.45 * * * \quad-.22 * * *$

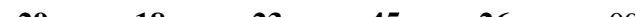

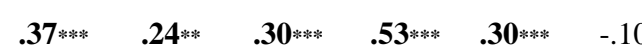

$\begin{array}{rllllll}.43 * * * & .29 * * * & .41 * * * & .73 * * * & .39 * * * & -.13 * & .58 * * *\end{array}$

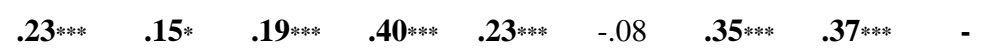

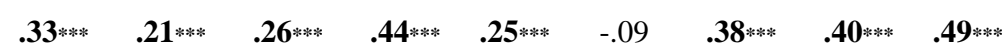

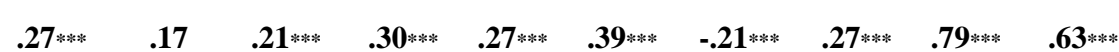

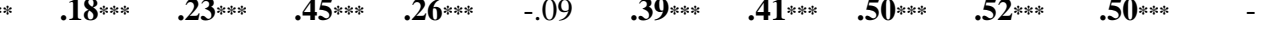

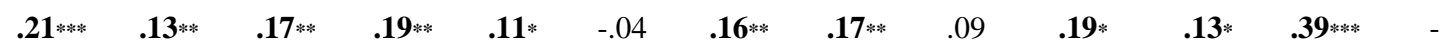

$.46 * * * \quad .48 * * * \quad .69 * * * \quad .56 * * *$

$.62 * * * \quad .66 * * * \quad .29 * * *$

$\begin{array}{lllllllll}-.05 & -.03 & -.04 & \mathbf{- . 1 4} * & -.08 & .03 & \mathbf{- . 1 2}\end{array}$

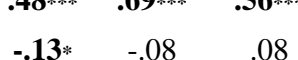

$\begin{array}{llll}-.05 & .05 & .36 * * * & .08\end{array}$

$\begin{array}{rllllll}. \mathbf{3 3} * * * & .21 * * * & .26 * * * & .33 * * * & .19 * * * & -.06 & .28 *\end{array}$

$\begin{array}{lllllllll}-.01 & -.01 & -.01 & \mathbf{- . 1 3} * & -.07 & .02 & \mathbf{- . 1 1}\end{array}$

$.67 * * * \quad .42 * * * \quad .53 * * * \quad .76 * * * \quad .44 * * * \quad-15 * \quad .66 * * *$

$.30 * * * \quad .34 * * * \quad .33 * * *$

$.29 * * * \quad .37$

$\begin{array}{llllllllll}\mathbf{- . 1 1} * & -.08 & .06 & -.05 & .01 & \mathbf{. 4 5} * * * & .07 & \mathbf{. 9 3} * * * & \mathbf{. 4 5} * * * & -\end{array}$

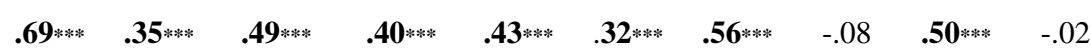

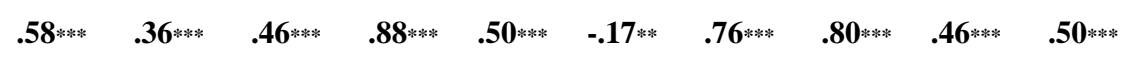

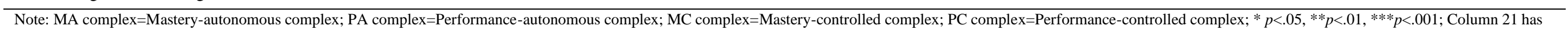
been omitted due to limitations of space. 


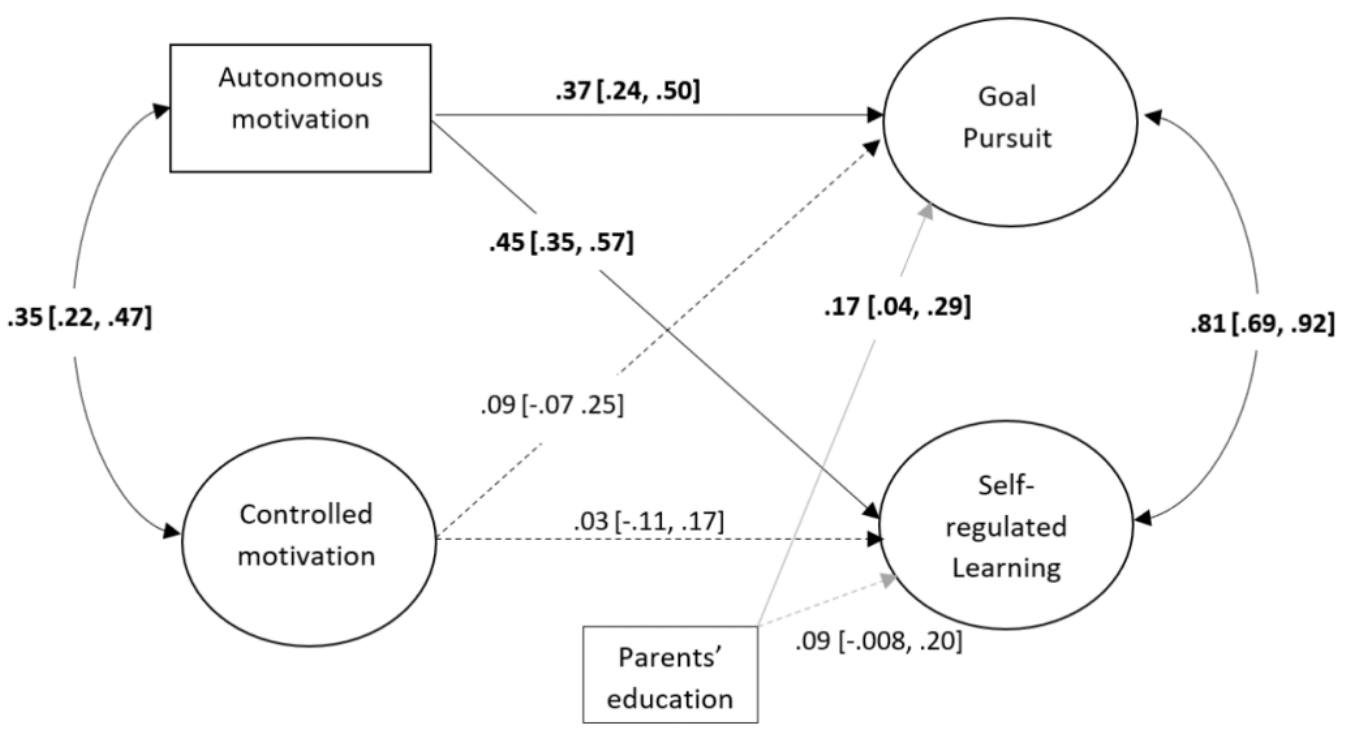

Figure 1. Structural equation model of relationship between autonomous and controlled motivation and goal pursuit and selfregulated learning. Parents' education was entered as a covariate. Standardized coefficients and $95 \%$ confidence intervals are reported. Double-headed arrows indicate covariances. Solid lines indicate a significant effect at $p<.05$.

When the mediation of attainment, utility, and interest value was included in the relationship between autonomous and controlled motivation and goal pursuit and self-regulated learning, the model fit was fair, $\mathrm{X}_{2}(240)=485.82, p<.001 ; \mathrm{RMSEA}=.053(90 \%$ CIs $[.046, .060]), \mathrm{CFI}=.94, \mathrm{SRMR}=.069$. The variance explained by the model for attainment value, utility value and interest value were $16 \%, 28 \%$ and $29 \%$ respectively. The variance explained within goal pursuit was $36 \%$ while the model explained $47 \%$ of the variance in self-regulated learning. The standardised model parameters for the $a$ paths $(x \rightarrow m), b$ paths $(m \rightarrow y)$, direct effects $(x \rightarrow y)$, and the indirect effects $(x \rightarrow m \rightarrow y)$, are presented in Table 3 .

Consistent with our hypotheses, autonomous motivation positively predicted attainment value, interest value, and utility value. Conversely, controlled motivation was negatively related to interest value and utility value but was unrelated to attainment value. It appears that autonomous motivation is a source of subjective value while more controlled motivation for academic goals is associated with perceptions of lower enjoyment and utility of academic tasks. Of the twelve indirect effects tested, only the indirect paths between autonomous motivation, attainment value and goal pursuit and self-regulated learning were significant. Accounting for parents' education, autonomous motivation also had a direct effect on goal pursuit and self-regulated learning, and there was a direct negative effect between controlled motivation and self-regulated

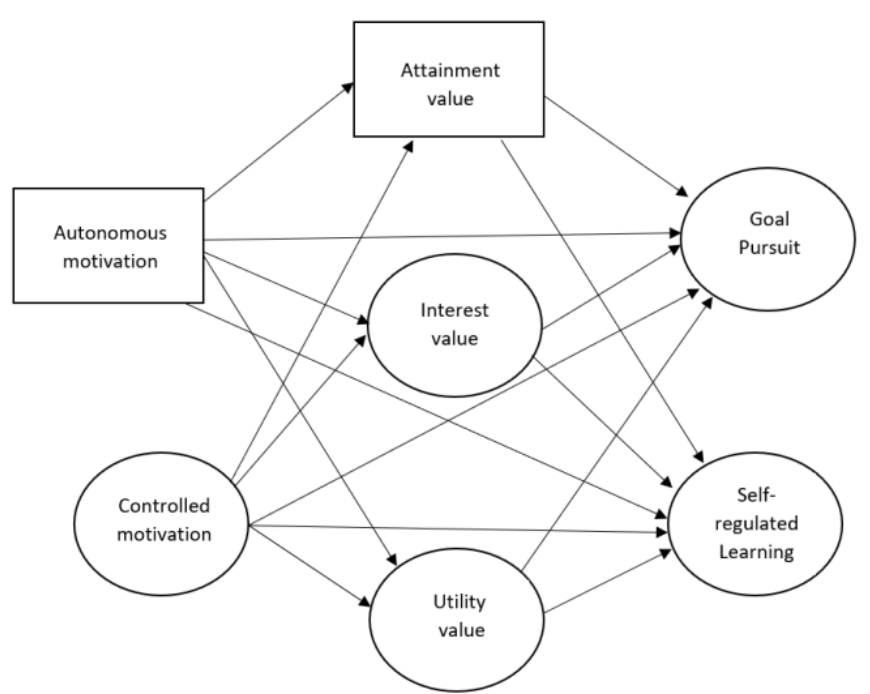

Figure 2. Hypothesized path model of the relationship between autonomous and controlled motivation, subjective values, goal pursuit, and self-regulated learning. Note: Parents' education was entered as a covariate but was not included here for clarity.

learning. It seems that as autonomous motivation increases, so do academic goal pursuit and selfregulated learning via a positive relationship with attainment value. The increased intrinsic value and utility value that occurs with increased autonomous motivation appears not to provide additional benefit beyond autonomous motivation themselves. 
Table 3. Parameter estimates of mediation SEM model

\begin{tabular}{|c|c|c|c|c|c|}
\hline & & Std $\beta$ & $S E$ & Sig & 95\% CIs \\
\hline \multicolumn{6}{|l|}{$a$ path $(x \rightarrow m)$} \\
\hline \multirow[t]{3}{*}{ Autonomous motivation } & Attainment value & .39 & .04 & $<.001$ & {$[.31, .48]$} \\
\hline & Interest Value & .53 & .04 & $<.001$ & {$[.44, .61]$} \\
\hline & Utility Value & .51 & .04 & $<.001$ & {$[.42, .59]$} \\
\hline \multirow[t]{4}{*}{ Controlled motivation } & Attainment value & -.05 & .05 & .352 & {$[-.14, .05]$} \\
\hline & Interest Value & -.11 & .05 & .035 & {$[-.22,-.008]$} \\
\hline & Utility Value & -.14 & .05 & .007 & {$[-.24,-.04]$} \\
\hline & & \multicolumn{4}{|c|}{ Goal pursuit } \\
\hline \multicolumn{6}{|l|}{$b$ path $(m \rightarrow y)$} \\
\hline & Attainment value & .34 & .09 & $<.001$ & {$[.17, .51]$} \\
\hline & Interest Value & -.09 & .21 & .682 & {$[-.50, .33]$} \\
\hline & Utility Value & .18 & .22 & .402 & {$[-.25, .61]$} \\
\hline \multicolumn{6}{|l|}{ Indirect effect $(x \rightarrow m \rightarrow y)$} \\
\hline Autonomous motivation $\rightarrow$ attainment value & & .13 & .04 & $<.001$ & {$[.06, .19]$} \\
\hline Autonomous motivation $\rightarrow$ interest value & & -.05 & .11 & .683 & {$[-.26, .17]$} \\
\hline Autonomous motivation $\rightarrow$ utility value & & .09 & .11 & .404 & {$[-.13, .31]$} \\
\hline Controlled motivation $\rightarrow$ attainment value & & -.02 & .02 & .364 & {$[-.05, .02]$} \\
\hline Controlled motivation $\rightarrow$ interest value & & .01 & .02 & .688 & {$[-.04, .06]$} \\
\hline Controlled motivation $\rightarrow$ utility value & & -.03 & .03 & .424 & {$[-.09, .04]$} \\
\hline \multicolumn{6}{|l|}{ Direct effect $(x \rightarrow y)$} \\
\hline & Autonomous motivation & .22 & .08 & .003 & {$[.08, .37]$} \\
\hline & Controlled motivation & -.11 & .07 & .102 & {$[-.24, .02]$} \\
\hline & Parents' education & .20 & .07 & .002 & {$[.008, .33]$} \\
\hline & & \multicolumn{4}{|c|}{ Self-regulated learning } \\
\hline \multicolumn{6}{|l|}{$b$ path $(m \rightarrow y)$} \\
\hline & Attainment value & .35 & .06 & $<.001$ & {$[.13, .29]$} \\
\hline & Interest Value & .15 & .09 & .102 & {$[-.03, .29]$} \\
\hline & Utility Value & -.03 & .10 & .750 & {$[-.18, .13]$} \\
\hline \multicolumn{6}{|l|}{ Indirect effect $(x \rightarrow m \rightarrow y)$} \\
\hline Autonomous motivation $\rightarrow$ attainment value & & .12 & .03 & $<.001$ & {$[.06, .17]$} \\
\hline Autonomous motivation $\rightarrow$ interest value & & .11 & .09 & .192 & {$[-.06, .28]$} \\
\hline Autonomous motivation $\rightarrow$ utility value & & .02 & .09 & .851 & {$[-.15, .18]$} \\
\hline Controlled motivation $\rightarrow$ attainment value & & -.01 & .02 & .359 & {$[-.04, .02]$} \\
\hline Controlled motivation $\rightarrow$ interest value & & -.02 & .02 & .262 & {$[-.07, .02]$} \\
\hline Controlled motivation $\rightarrow$ utility value & & -.004 & .02 & .754 & {$[-.05, .04]$} \\
\hline \multicolumn{6}{|l|}{ Direct path $(x \rightarrow y)$} \\
\hline & Autonomous motivation & .24 & .06 & $<.001$ & {$[.13, .35]$} \\
\hline & Controlled motivation & -.19 & .05 & $<.001$ & {$[-.30,-.09]$} \\
\hline & Parents' education & .14 & .05 & .005 & {$[.04, .24]$} \\
\hline
\end{tabular}




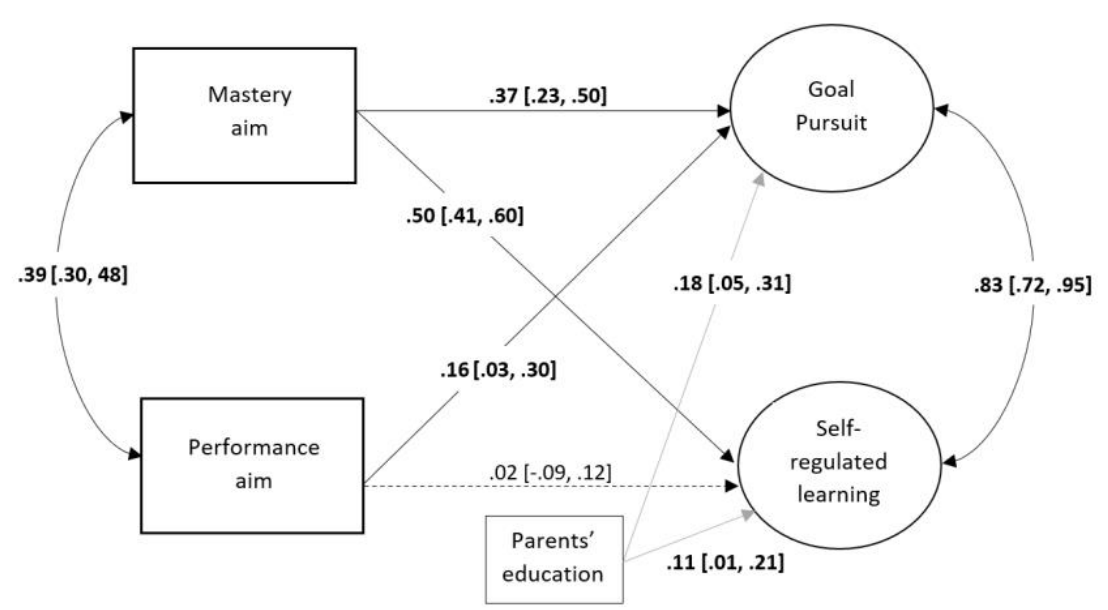

Figure 3. Structural equation model of relationship between mastery and achievement goals and goal pursuit and selfregulated learning. Parents' education was entered as a covariate. Standardized coefficients and $95 \%$ confidence intervals are reported. Double-headed arrows indicate covariances. Solid lines indicate a significant effect at $p<.05$.

\section{Achievement Aims, Goal Pursuit, and Self-Regulated Learning}

As presented in Figure 3, we then used SEM to assess the individual influence of achievement aims on goal pursuit and self-regulated learning. The model fit was good, $\mathrm{X}_{2}(38)=86.67, p<.001 ;$ RMSEA $=.059$ $(90 \%$ CI $[.043, .076]) ;$ CFI $=.95 ;$ SRMR $=.040$. The model explained $24 \%$ of the variance of goal pursuit and $27 \%$ of the variance of self-regulated learning. Consistent with our hypotheses, results suggest that both mastery and performance aims significantly predicted goal pursuit, and that mastery aims positively predicted self-regulated learning. These findings indicate that as mastery aims increase, so does engagement in academic goal pursuit and selfregulated learning strategies, whereas having performance aims is related to engagement in goal pursuit, albeit to a lesser extent.

\section{Goal Complexes, Goal Pursuit, and Self-Regulated Learning}

To test the effect of the combination of what and why on academic goal pursuit, a SEM model was conducted where the aims-motivation goal complexes were entered as predictors of goal pursuit and selfregulated learning (see Figure 4). After establishing the measurement model, model fit indices suggested there was adequate model fit, $X_{2}(419)=928.18, p<.001$, RMSEA $=.058(90 \%$ CIs $[.053, .063])$, CFI $=.95$, SRMR $=.121$. The model accounted for $39 \%$ of the variance in goal pursuit and $41 \%$ of the variance of self- regulated learning. As hypothesised, the masteryautonomous complex predicted goal pursuit and selfregulated learning. Unexpectedly, there was no relationship between performance-autonomous complexes and goal pursuit. Goal pursuit and selfregulated learning were also unrelated to the masterycontrolled or performance-controlled complexes. These results indicate that greater goal pursuit and selfregulation are more likely with combined mastery aims and autonomous motivation.

\section{Goal Complexes, Values, Goal Pursuit, and Self- Regulated Learning}

An exploratory analysis was then undertaken to assess the mediating role of values in the relationship between goal complexes and goal pursuit and selfregulated learning. A model was tested where the relationships between mastery-autonomous, masterycontrolling, performance-autonomous, and performance-controlling complexes and goal pursuit and self-regulated learning, were mediated by attainment, utility, and interest values. The model is illustrated in Figure 5. Model fit for this model was satisfactory, $\mathrm{X}_{2}(787)=1499.01, p<.001, \mathrm{RMSEA}=.05$ $(90 \%$ CIs $[.046, .054]), \mathrm{CFI}=.95, \mathrm{SRMR}=.112$.

The mastery-autonomy complex accounted for $44 \%$ of the variance of utility value, $57 \%$ of the variance of interest value, and $30 \%$ of the variance of attainment value. The model accounted for $49 \%$ of the variance of goal pursuit and $57 \%$ of the variance of self-regulated learning. The standardised model parameters for the $a$ paths $(x \rightarrow m), b$ paths $(m \rightarrow y)$, the direct effects $(x \rightarrow y)$, and the indirect effects $(x \rightarrow m \rightarrow y)$, are presented in Table 4. 


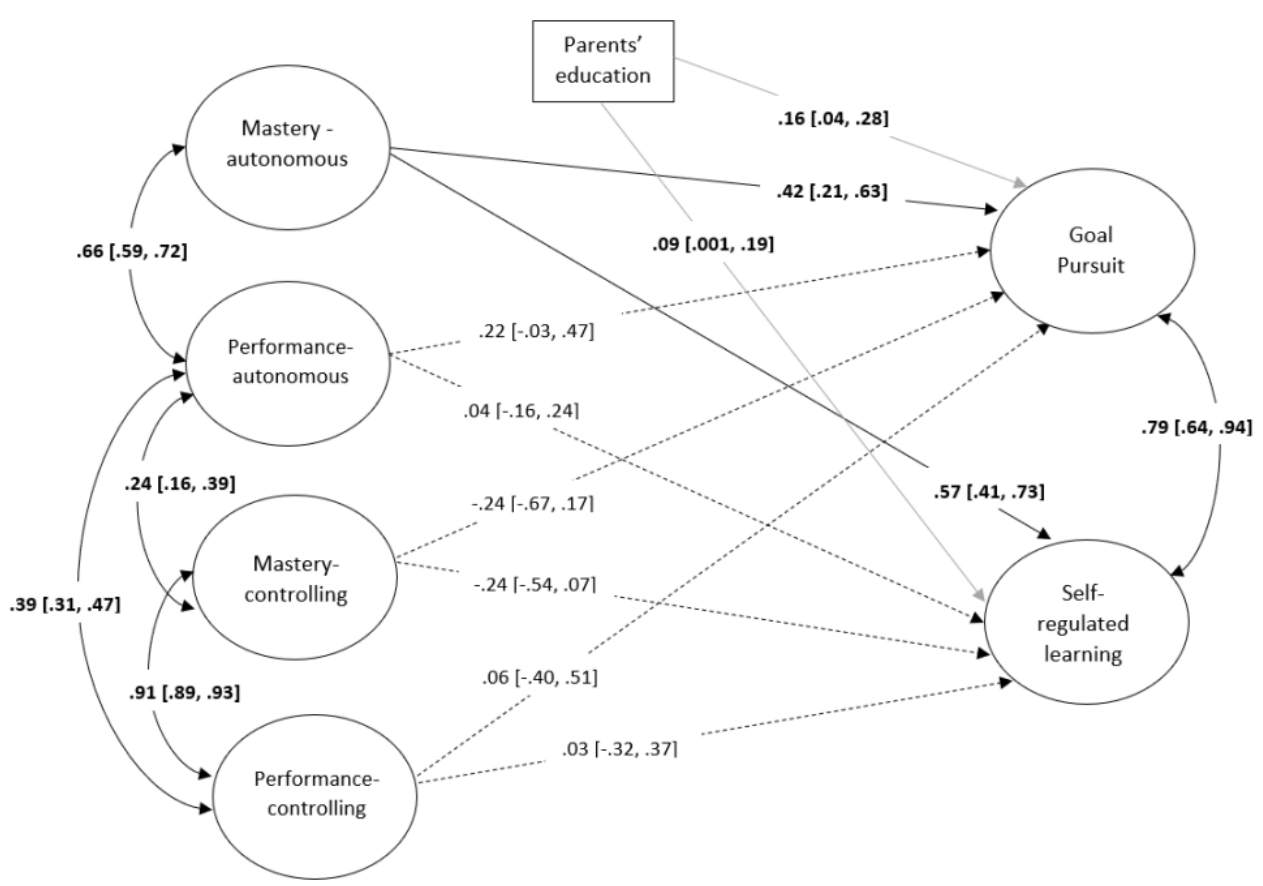

Figure 4. Structural equation model of relationship between goal complexes and goal pursuit and self-regulated learning. Parents' education was entered as a covariate. Standardized coefficients and $95 \%$ confidence intervals are reported. Doubleheaded arrows indicate covariances. Solid lines indicate a significant effect at $p<.05$

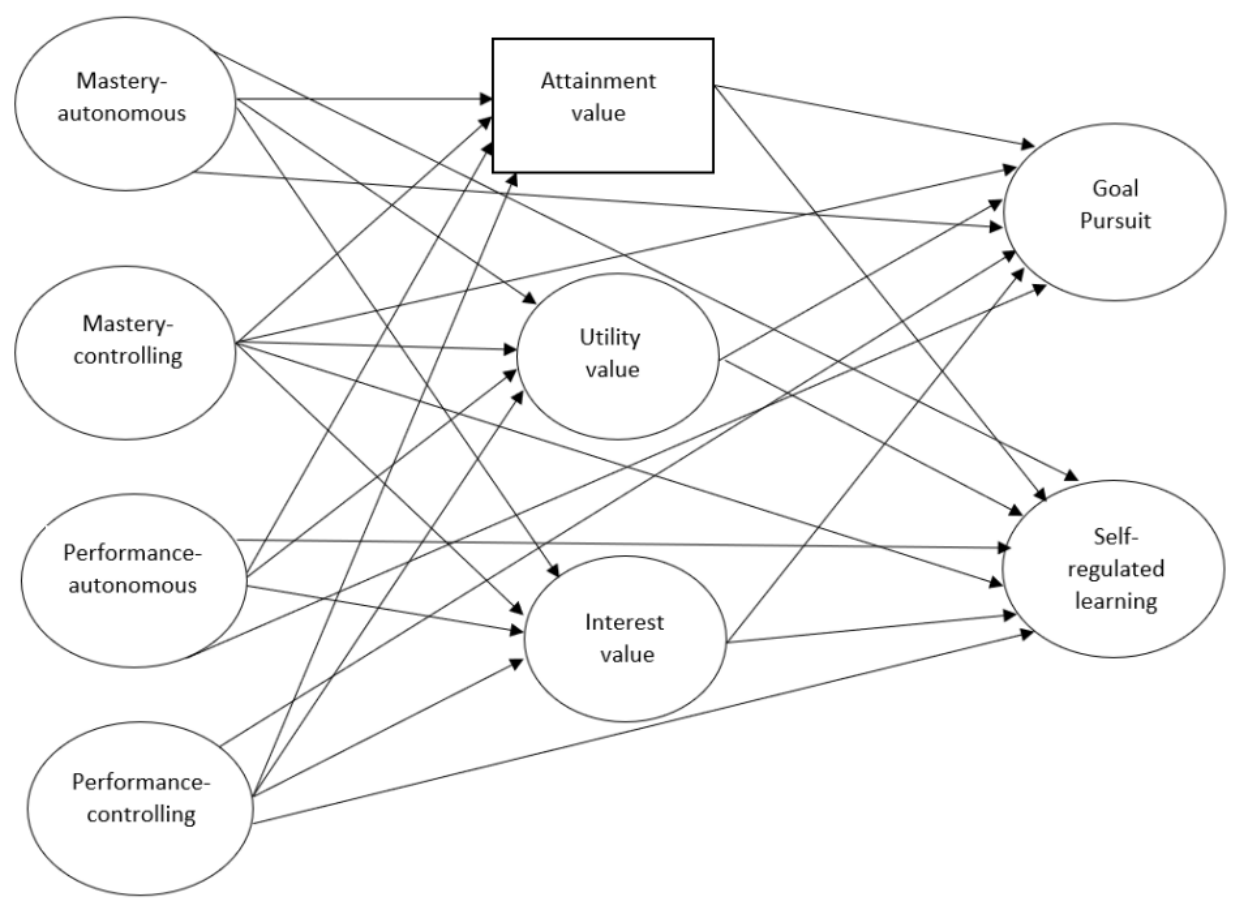

Figure 5. Illustrative path model of the relationships between goal complexes, subjective values, goal pursuit, and self-regulated learning. Note: Parents' education (entered as a covariate) and covariances are not presented in this figure to retain clarity. 
Table 4. Standardised parameter estimates of goal complex mediation SEM model

\begin{tabular}{|c|c|c|c|c|c|}
\hline & & Std $\beta$ & $S E$ & Sig & $95 \%$ CIs \\
\hline \multicolumn{6}{|l|}{$a$ path $(x \rightarrow m)$} \\
\hline \multirow[t]{3}{*}{ Mastery-autonomous } & Attainment value & .63 & .08 & $<.001$ & {$[.46, .79]$} \\
\hline & Interest Value & .82 & .08 & $<.001$ & {$[.66, .98]$} \\
\hline & Utility Value & .73 & .09 & $<.001$ & {$[.56, .91]$} \\
\hline \multirow[t]{3}{*}{ Mastery-controlling } & Attainment value & -.006 & .16 & .967 & {$[-.31, .30]$} \\
\hline & Interest Value & -.09 & .15 & .549 & {$[-.39, .21]$} \\
\hline & Utility Value & -.11 & .16 & .520 & {$[-.42, .21]$} \\
\hline \multirow[t]{3}{*}{ Performance-autonomous } & Attainment value & -.12 & .10 & .225 & {$[-.32, .08]$} \\
\hline & Interest Value & -.13 & .10 & .195 & {$[-.33, .07]$} \\
\hline & Utility Value & -.16 & .11 & .150 & {$[-.37, .06]$} \\
\hline \multirow[t]{4}{*}{ Performance-controlling } & Attainment value & .08 & .18 & .660 & {$[-.27, .42]$} \\
\hline & Interest Value & .005 & .17 & .977 & {$[-.34, .07]$} \\
\hline & Utility Value & .04 & .19 & .841 & {$[-.33, .40]$} \\
\hline & & \multicolumn{4}{|c|}{ Goal pursuit } \\
\hline \multicolumn{6}{|l|}{$b$ path $(m \rightarrow y)$} \\
\hline Attainment value & & .29 & .09 & .001 & {$[.11, .46]$} \\
\hline Interest Value & & -.45 & .26 & .080 & {$[-.96, .05]$} \\
\hline Utility Value & & .33 & .23 & .146 & {$[-.12, .78]$} \\
\hline \multicolumn{6}{|l|}{ Indirect effect $(x \rightarrow m \rightarrow y)$} \\
\hline Mastery-autonomous $\rightarrow$ attainment value & & .18 & .06 & .003 & {$[.06, .30]$} \\
\hline Mastery-autonomous $\rightarrow$ interest value & & -.37 & .22 & .090 & {$[-.80, .06]$} \\
\hline Mastery-autonomous $\rightarrow$ utility value & & .24 & .17 & .152 & {$[-.09, .58]$} \\
\hline Mastery-controlling $\rightarrow$ attainment value & & -.002 & .05 & .967 & {$[-.09, .09]$} \\
\hline Mastery-controlling $\rightarrow$ interest value & & .04 & .07 & .573 & {$[-.10, .18]$} \\
\hline Mastery-controlling $\rightarrow$ utility value & & -.04 & .06 & .555 & {$[-.15, .08]$} \\
\hline Performance-autonomous $\rightarrow$ attainment value & & -.04 & .03 & .253 & {$[-.10, .03]$} \\
\hline Performance-autonomous $\rightarrow$ interest value & & .06 & .06 & .309 & {$[-.06, .18]$} \\
\hline Performance-autonomous $\rightarrow$ utility value & & -.05 & .05 & .305 & {$[-.15, .05]$} \\
\hline Performance-controlling $\rightarrow$ attainment value & & .02 & .05 & .662 & {$[-.08, .12]$} \\
\hline Performance-controlling $\rightarrow$ interest value & & -.002 & .08 & .977 & {$[-.16, .15]$} \\
\hline Performance -controlling $\rightarrow$ utility value & & .01 & .06 & .843 & {$[-.11, .13]$} \\
\hline \multicolumn{6}{|l|}{ Direct effect $(x \rightarrow y)$} \\
\hline Mastery-autonomous & & .40 & .16 & .014 & {$[.08, .71]$} \\
\hline Mastery-controlling & & -.25 & .20 & .214 & {$[-.65, .15]$} \\
\hline Performance-autonomous & & .21 & .13 & .105 & {$[-.04, .47]$} \\
\hline Performance-controlling & & .05 & .23 & .841 & {$[-.41, .50]$} \\
\hline \multirow[t]{2}{*}{ Parents' education } & & .17 & .07 & .010 & {$[.04, .30]$} \\
\hline & & \multicolumn{4}{|c|}{ Self-regulated learning } \\
\hline \multicolumn{6}{|l|}{$b$ path $(m \rightarrow y)$} \\
\hline Attainment value & & .25 & .07 & $<.001$ & {$[.12, .38]$} \\
\hline Interest Value & & -.16 & .20 & .408 & {$[-.55, .22]$} \\
\hline Utility Value & & .21 & .17 & .232 & {$[-.13, .55]$} \\
\hline \multicolumn{6}{|l|}{ Indirect effect $(x \rightarrow m \rightarrow y)$} \\
\hline Mastery-autonomous $\rightarrow$ attainment value & & .16 & .05 & .001 & {$[.07, .25]$} \\
\hline Mastery-autonomous $\rightarrow$ interest value & & -.13 & .16 & .415 & {$[-.46, .19]$} \\
\hline
\end{tabular}




\begin{tabular}{lcccc}
\hline Mastery-autonomous $\rightarrow$ utility value & .15 & .13 & .235 & {$[-.10, .40]$} \\
Mastery-controlling $\rightarrow$ attainment value & -.002 & .04 & .967 & {$[-.08, .08]$} \\
Mastery-controlling $\rightarrow$ interest value & .02 & .03 & .635 & {$[-.05, .08]$} \\
Mastery-controlling $\rightarrow$ utility value & -.02 & .04 & .569 & {$[-.10, .05]$} \\
Performance-autonomous $\rightarrow$ attainment value & -.03 & .03 & .240 & {$[-.08, .02]$} \\
Performance-autonomous $\rightarrow$ interest value & .02 & .03 & .503 & {$[-.04, .09]$} \\
Performance-autonomous $\rightarrow$ utility value & -.03 & .03 & .352 & {$[-.10, .04]$} \\
Performance-controlling $\rightarrow$ attainment value & .02 & .04 & .661 & {$[-.07, .11]$} \\
Performance-controlling $\rightarrow$ interest value & -.001 & .03 & .977 & {$[-.06, .06]$} \\
Performance -controlling $\rightarrow$ utility value & .01 & .04 & .843 & {$[-.07, .08]$} \\
Direct effect $(\boldsymbol{x} \rightarrow \boldsymbol{y})$ & & & & \\
Mastery-autonomous & .47 & .13 & $<.001$ & {$[.22, .72]$} \\
Mastery-controlling & -.25 & .16 & .107 & {$[-.56, .05]$} \\
Performance-autonomous & .07 & .10 & .492 & {$[-.13, .27]$} \\
Performance-controlling & .005 & .18 & .978 & {$[-.34, .35]$} \\
Parents' education & .10 & .05 & .040 & {$[.004, .20]$} \\
\hline
\end{tabular}


The mastery-autonomous complex predicated attainment, utility, and interest value. Only the indirect paths between the mastery-autonomous complex, attainment value, and goal pursuit and self-regulated learning were significant. There was also a direct effect of mastery-autonomous complex on goal pursuit and self-regulated learning. Therefore, as masteryautonomous complex increases, so do academic goal pursuit and self-regulated learning via a partial mediation relationship with attainment value.

\section{Discussion}

The purpose of the present research was to examine the relationship between the what and why of pursuing academic goals, subjective value, and goal pursuit and self-regulated learning. This was assessed in a number of ways. First, the direct association between motivation and goal pursuit and self-regulated learning was examined. Then, the mediating role of subjective values between motivation and goal pursuit and selfregulated learning strategies was tested. The independent contribution of achievement aims to goal pursuit and self-regulated learning was evaluated. The association between the outcomes and underlying motivation for achievement aims was assessed with goal complexes. Finally, the mediating role of subjective values in the relationship between goal complexes and the outcomes was examined in an integrative framework.

In support of hypothesis 1a-e, autonomous motivation predicted goal pursuit, self-regulated learning, and each of the subjective values. Only attainment value partially mediated the relationship between autonomous motivation and goal pursuit and self-regulated learning, providing support for hypothesis $2 \mathrm{~b}$ but not hypotheses $2 \mathrm{a}$ and $2 \mathrm{~b}$. Unexpectedly, controlled motivation was negatively related to interest and utility value, and self-regulated learning, although there were no indirect effects. Mastery aims predicted goal pursuit and self-regulated learning, while performance aims predicted goal pursuit to a lesser extent, in support of hypotheses $3 \mathrm{a}-\mathrm{c}$. In support of hypotheses $4 \mathrm{a}, 4 \mathrm{c}, 5 \mathrm{c}$ and $5 \mathrm{~d}$, mastery-autonomous complexes predicted goal pursuit and self-regulated learning, and attainment value mediated these relationships. Contrary to hypotheses $5 \mathrm{a}, 5 \mathrm{~b}, 5 \mathrm{e}$, and $5 \mathrm{f}$, the current research did not find that the performance-autonomous complex was related to goal pursuit, self-regulated learning, or subjective values.

\section{Motivation for Goal Pursuit and Subjective Value}

Our findings add to the expanding literature demonstrating the positive effect of autonomous motivation on goal pursuit and self-regulated learning (Black \& Deci, 2000; Guay et al., 2010; Milyavskaya et al., 2015; Vansteenkiste et al., 2006, 2009; Werner et al., 2016, 2018). Additionally, the results support past research demonstrating that controlled motivation is unhelpful for goal pursuit and can be detrimental to self-regulated learning (Brunet et al., 2015; Donche et al., 2013; Koestner et al., 2008; Milyavskaya et al., 2015). The findings are consistent with theoretical developments that identify motivation for goal pursuit as a source of subjective value in decisions between behavioural options (Berkman et al., 2017; Eccles \& Wigfield, 2002; Milyavskaya \& Inzlicht, 2018). While autonomous motivation was positively related to the attainment, interest, and utility value for one's major, there was a negative association between controlled motivation and interest and utility value. Our results indicate that higher salience of attainment value, the value of the task in affirming self-identity, is related to more goal pursuit and utilization of self-regulated learning strategies.

On the other hand, the findings that higher interest or utility value are not necessarily associated with more studying efforts was not consistent with the study hypotheses. Previous research has demonstrated that there are associations between interest and utility values and persistence, grades, and continued pursuit of the academic subject within education and as a career (Gaspard et al., 2018; Perez et al., 2014, 2019; Robinson et al., 2019; Simons et al., 2003; Tulis \& Fulmer, 2013; Wu \& Fan, 2017). Previous research does not often examine the relationship between outcomes and all three components (interest, attainment, utility) of subjective task value within one model and they are often combined to form a "subjective value" construct. Of note are the high mean scores of subjective values in this study (attainment value $M=5.77$; interest value $M=5.79$; utility value $M=5.49$ of $1-7$ scale range). Additionally, the subject values were highly correlated with each other $(r s=.49$ - .79) which may have made it difficult to extricate the independent contributions of each to the variance of goal pursuit and self-regulated learning. Indeed, when examined separately in correlational analyses, all three had moderate positive correlations with the outcomes (see Table 2).

That said, weaker associations have been observed between utility value and grades than other subjective values (Gaspard et al., 2018; Perez et al., 2019; 
Robinson et al., 2019). Utility value signals the value of academic tasks for everyday use and for longer term goals, and is more strongly associated with more motivational conflict and weaker self-control than interest value (Galla, Amemiya, \& Wang, 2018). However, given that interest value is less strongly related to motivational conflict than utility value, and that it signifies experiencing immediate reward from the task (Galla et al., 2018), it is less clear why it did not predict either outcome. It may also be that high utility value and intrinsic value did not provide additional benefit for goal pursuit and self-regulated learning over and above the effects of high attainment value, as has been previously suggested (Robinson et al., 2019). Longitudinal research has demonstrated that utility and interest value are more sensitive to changes in motivation than attainment value, which has greater stability (Robinson et al., 2019). Accordingly, utility value demonstrated the steepest decline over time as school year progressed in college students (Robinson et al., 2019).

\section{Achievement Aims and their Underlying Motivation}

The positive relationship between mastery aims and the outcomes and the smaller effect of performance aims on goal pursuit is consistent with previous research (Dweck \& Leggett, 1988; Hulleman et al., 2010; Rawsthorne \& Elliot, 1999). Furthermore, the goal complex theory and previous findings suggest that mastery or performance goals pursued for the same underlying motives have similar effects on outcomes (Elliot \& Thrash, 2001; Harackiewicz, Barron, \& Elliot, 1998; Murayama, Elliot, \& Yamagata, 2011; Senko \& Tropiano, 2016; Vansteenkiste, Lens, Elliot, Soenens, \& Mouratidis, 2014). This is said to be particularly true for mastery and performance aims pursued for autonomous motives (Gaudreau, 2012; Senko \& Tropiano, 2016). While performance aims pursued for purely autonomous motives may be adaptive (Dweck \& Leggett, 1988; Hulleman et al., 2010), goals are pursued for multiple motives and it may be unlikely that a performance goal will be pursued for autonomous motivation only. Meanwhile, mastery goals are primarily pursued for autonomous motives (Michou et al., 2014). The present study, however, is the first study to include the four motivations-aims complexes within one comprehensive SEM model. Therefore, it may be that when the mastery-autonomous complex is accounted for within a model, the effects observed by previous research (i.e., the potential positive effects of autonomous performance aims) do not emerge.

Still, controlled motivation was very highly correlated with both the mastery-controlled and performance-controlled complexes $(r=.97$ and $r=.90$ respectively), and the controlled motivation complexes were also very highly related to each other $(r=.93)$. Meanwhile, autonomous motivation was highly correlated with the mastery-autonomous complex $(r=.77)$, but relatively less correlated with the performance-autonomous complex $(r=.42)$. The correlations between controlled motivation and the controlled motivation complexes suggest that they are measuring the same construct. Therefore, an investigation of how participants make judgements about the extent to which aims are being pursued for autonomous or controlled reasons is warranted. An examination of participants' ratings and judgement of mastery-avoidance items has been conducted previously (Ciani \& Sheldon, 2010), and the same methods could be a useful to assess participants' understanding of items for controlled motivation complexes.

\section{Theoretical and Practical Implications}

The findings of this study are consistent with theoretical developments that identify motivational constructs as a source of subjective value in decisions between behavioural options (Berkman et al., 2017; Eccles \& Wigfield, 2002; Milyavskaya \& Inzlicht, 2018). Furthermore, this was the first study to examine the relationship between subjective task values, goal complexes and outcomes. This resulted in the presentation of an integrative framework to account for goal pursuit and self-regulated learning. The masteryautonomous complex contributed more variance to subjective task values than autonomous motivation alone. Additionally, more variance was accounted for in goal pursuit and self-regulated learning ( $R_{2}$ increase of $10 \%$ and $16 \%$ respectively) by the mediation relationship between goal complexes and subjective task values than the mediation relationship between motivation, subjective values, and the outcomes. Our results indicate that both mastery aims and autonomous motivation are sources of subjective values. Nonetheless, given that neither mastery-controlled and performance-autonomous complexes were not related to subjective values, it seems that the combined effects of having mastery aims for underlying autonomous motives was more important than motivation or aims alone. 
The partial mediation by attainment value between autonomous motivation and the mastery-autonomous complex with the two outcomes is consistent with previous research and theoretical assumptions about the salience of identity-related motivation in academic goal pursuit (Berkman et al., 2017; Eccles, 2009; Robinson et al., 2019; Robinson, Perez, Nuttall, Roseth, \& Linnenbrink-Garcia, 2018). Enhancing the salience of the self-relevance of academic goal behaviours and self-regulated learning may increase attainment value and autonomous motivation, particularly integrated motivation. This, in turn, may increase engagement in goal pursuit and self-regulated learning strategies. Yet, there are broader implications of these findings beyond academic goal pursuit. More generally, increasing the salience of self-relevance for goal-related behaviours will increase the subjective value of the behaviours and promote the successful application of self-control (Dominick \& Cole, 2020).

The implications of the findings of this study are that students in the classroom should be encouraged to develop autonomous motivation and pursue mastery goals. Establishing classroom environments which satisfy basic psychological needs could be one way to achieve this. Autonomy-supportive and relatednesssupportive environments increase autonomous motivation, which in turn increases mastery aims but not performance aims (Ciani et al., 2011). In addition, perceived teacher autonomy support prevented the decline of mastery aims over the course of a semester (but had no effect on performance aims; Ciani et al., 2011).

\section{Limitations and Future Directions}

The limitations of this research need to be considered. First, this study used a cross-sectional design and so the variables were only measured at one time point. While the results generally support the causal directions proposed by theory and previous research, we cannot infer causal relations from our findings. It would be useful to conduct future studies that examine the dynamic relationships between the variables, particularly how subjective value, goal pursuit and self-regulated learning vary based on fluctuations in motivation and goal complexes. Second, the internal consistency of the autonomous motivation, attainment value, and achievement aims' measures were below desirable levels $\left(r_{\mathrm{SB}}<.70\right)$. This increases measurement error and means that these variables may not have been measured precisely. The implications of this are that the effect sizes of relationships may have been underestimated (Buzas, Stefanski, \& Tosteson, 2014). Future research should confirm the findings in this study. Third, this study sampled Canadian students whose major was Psychology. Thus, the majority of the participants in this sample were female, as is common with undergraduate psychology courses. Gender may play a role in development of subjective value (Wang et al., 2015) and affect social desirability of reporting the pursuit of performance aims for autonomous motives (Senko \& Hulleman, 2013; Senko \& Tropiano, 2016). Future research should further examine the role of motivation in subjective value, goal complexes, goal pursuit and self-regulated learning in college students pursuing a different major and in other samples, such as working adults. Further research could also examine the role of motivation and goal complexes on opportunity and effort costs, and could employ objective measures of goal progress such as grades.

\section{Conclusion}

The findings of this study support value-based theory and self-determination theory by illustrating that motivation has an underlying role in subjective value and achievement aims. Autonomous motivation and mastery aims were both important in predicting subjective values, goal pursuit, and self-regulated learning. Providing students with autonomy supportive environments to cultivate autonomous motivation may help to develop attainment value and preserve utility and intrinsic value. Enhancing autonomous motivation may also make it more likely that mastery aims are developed as opposed to performance aims. Taken together, our findings suggest that the key to students' ability to employ self-regulatory strategies in the face of a potential motivational conflict is the development of mastery aims and autonomous motivation. The conclusions drawn from this study may also apply to goal pursuit more broadly.

\section{References}

Achtziger, A., \& Gollwitzer, P. M. (2008). Motivation and Volition in the Course of Action. In J. Heckhausen \& H. Heckhausen (Eds.), Motivation and Action (pp. 272-295). Cambridge: Cambridge University Press. https://doi.org/10.1017/CBO9780511499821.012

Barrett, P. (2007). Structural equation modelling: Adjudging model fit. Personality and Individual Differences, 42(5), 815-824. https://doi.org/10.1016/j.paid.2006.09.018

Benita, M., Roth, G., \& Deci, E. L. (2014). When are mastery goals more adaptive? It depends on experiences of autonomy support and autonomy. Journal of Educational Psychology, 106(1), 258267. https://doi.org/10.1037/a0034007 
Bentler, P. M., \& Bonett, D. G. (1980). Significance tests and goodness of fit in the analysis of covariance structures. Psychological Bulletin, 88(3), 588-606. https://doi.org/10.1037/0033-2909.88.3.588

Berkman, E. T., Hutcherson, C. A., Livingston, J. L., Kahn, L. E., \& Inzlicht, M. (2017). Self-Control as Value-Based Choice. Current Directions in Psychological Science, 26(5), 422-428. https://doi.org/10.1177/0963721417704394

Black, A. E., \& Deci, E. L. (2000). The effects of instructors' autonomy support and students' autonomous motivation on learning organic chemistry: A self-determination theory perspective. Science Education, 84(6), 740-756.

Browne, M. W., \& Cudeck, R. (1992). Alternative Ways of Assessing Model Fit. Sociological Methods \& Research, 21(2), 230-258.

Browne, M. W., \& Cudeck, R. (1993). Testing structural equation models (A. Bollen \& J. S. Long, Eds.). Newbury Park, CA: Sage.

Brunet, J., Gunnell, K. E., Gaudreau, P., \& Sabiston, C. M. (2015). An integrative analytical framework for understanding the effects of autonomous and controlled motivation. Personality and Individual Differences, 84, 2-15.

Buzas, J. S., Stefanski, L. A., \& Tosteson, T. D. (2014). Measurement Error. In W. Ahrens \& I. Pigeot (Eds.), Handbook of Epidemiology (pp. 1241-1282). New York, NY: Springer New York.

Carver, C. S., \& Scheier, M. F. (1998). On the Self-regulation of Behaviour. New York: Cambridge University Press.

Ciani, K. D., \& Sheldon, K. M. (2010). Evaluating the masteryavoidance goal construct: A study of elite college baseball players. Psychology of Sport and Exercise, 11(2), 127-132.

Ciani, K. D., Sheldon, K. M., Hilpert, J. C., \& Easter, M. A. (2011). Antecedents and trajectories of achievement goals: A selfdetermination theory perspective: Achievement goals. British Journal of Educational Psychology, 81(2), 223-243.

de Bruijn-Smolders, M., Timmers, C. F., Gawke, J. C. L., Schoonman, W., \& Born, M. Ph. (2016). Effective selfregulatory processes in higher education: Research findings and future directions. A systematic review. Studies in Higher Education, 41(1), 139-158.

Deci, E. L., \& Ryan, R. M. (2000). The "What" and "Why" of Goal Pursuits: Human Needs and the Self-Determination of Behavior. Psychological Inquiry, 11(4), 227-268.

Dominick, J. K., \& Cole, S. (2020). Goals as identities: Boosting perceptions of healthy-eater identity for easier goal pursuit. Motivation and Emotion, 44(3), 410-426.

Donche, V., De Maeyer, S., Coertjens, L., Van Daal, T., \& Van Petegem, P. (2013). Differential use of learning strategies in first-year higher education: The impact of personality, academic motivation, and teaching strategies. British Journal of Educational Psychology, 83(2), 238-251.

Dweck, C. S. (1986). Motivational processes affecting learning. American Psychologist, 41(10), 1040-1048.

Dweck, C. S., \& Leggett, E. L. (1988). A social-cognitive approach to motivation and personality. Psychological Review, 95(2), 256-273.

Eccles, J. S. (2009). Who Am I and What Am I Going to Do With My Life? Personal and Collective Identities as Motivators of Action. Educational Psychologist, 44(2), 78-89.

Eccles, J. S., O’Neill, S. A., \& Wigfield, A. (2005). Ability SelfPerceptions and Subjective Task Values in Adolescents and Children. In K. A. Moore \& L. H. Lippman (Eds.), What Do Children Need to Flourish? (pp. 237-249). Springer US.

Eccles, J. S., \& Wigfield, A. (2002). Motivational Beliefs, Values, and Goals. Annual Review of Psychology, 53(1), 109-132.
Eccles, J. S., Wigfield, A. S., Adler, T. F., Goff, S. B., \& Kaczala, C. M. (1983). Expectancies, values, and academic behaviors. In J. T. Spence (Ed.), Achievement and Achievement Motivation (pp. 75-146). San Francisco: Freeman.

Elliot, A. J. (1999). Approach and avoidance motivation and achievement goals. Educational Psychologist, 34(3), 169-189.

Elliot, A. J. (2005). A conceptual history of the achievement goal construct. In A. J. Elliot \& C. S. Dweck (Eds.), Handbook of competence and motivation (pp. 52-72). New York, NY: The Guilford Press.

Elliot, A. J., McGregor, H. A., \& Gable, S. (1999). Achievement goals, study strategies, and exam performance: A mediational analysis. Journal of Educational Psychology, 91(3), 549-563.

Elliot, A. J., \& Murayama, K. (2008). On the measurement of achievement goals: Critique, illustration, and application. Journal of Educational Psychology, 100(3), 613-628.

Elliot, A. J., \& Thrash, T. M. (2001). Achievement goals and the hierarchical model of achievement motivation. Educational Psychology Review, 13(2), 139-156.

Faul, F., Erdfelder, E., Buchner, A., \& Lang, A.-G. (2009). Statistical power analyses using $G^{*}$ Power 3.1: Tests for correlation and regression analyses. Behavior Research Methods, 41(4), 1149-1160.

Feather, N. T. (1982). Human values and the prediction of action: An expectancy-value analysis. In N. T. Feather (Ed.), Expectations and actions: Expectancy-value models in psychology (pp. 263-289). Hillsdale, NJ: Erlbaum.

Fishbach, A., Eyal, T., \& Finkelstein, S. R. (2010). How Positive and Negative Feedback Motivate Goal Pursuit: Feedback Motivates Goal Pursuit. Social and Personality Psychology Compass, 4(8), 517-530.

Fortier, M. S., Vallerand, R. J., \& Guay, F. (1995). Academic Motivation and School Performance: Toward a Structural Model. Contemporary Educational Psychology, 20(3), 257-274.

Galla, B. M., Amemiya, J., \& Wang, M.-T. (2018). Using expectancy-value theory to understand academic self-control. Learning and Instruction, 58, 22-33.

Gaspard, H., Wigfield, A., Jiang, Y., Nagengast, B., Trautwein, U., \& Marsh, H. W. (2018). Dimensional comparisons: How academic track students' achievements are related to their expectancy and value beliefs across multiple domains. Contemporary Educational Psychology, 52, 1-14.

Gaudreau, P. (2012). Goal self-concordance moderates the relationship between achievement goals and indicators of academic adjustment. Learning and Individual Differences, 22(6), 827-832.

Gollwitzer, P. M. (1990). Action phases and mind-sets. In Handbook of motivation and cognition: Foundations of social behavior, Vol. 2. (pp. 53-92). New York, NY, US: The Guilford Press.

Gollwitzer, P. M. (1993). Goal Achievement: The Role of Intentions. European Review of Social Psychology, 4(1), 141185.

Grant, H., \& Dweck, C. S. (2003). Clarifying Achievement Goals and Their Impact. Journal of Personality and Social Psychology, 85(3), 541-553.

Guay, F., Ratelle, C. F., Roy, A., \& Litalien, D. (2010). Academic self-concept, autonomous academic motivation, and academic achievement: Mediating and additive effects. Learning and Individual Differences, 20(6), 644-653.

Hagemeier, N. E., \& Murawski, M. M. (2014). An Instrument to Assess Subjective Task Value Beliefs Regarding the Decision to Pursue Postgraduate Training. American Journal of Pharmaceutical Education, 78(1), 11. 
Harackiewicz, J. M., Barron, K. E., \& Elliot, A. J. (1998). Rethinking achievement goals: When are they adaptive for college students and why? Educational Psychologist, 33(1), 121.

Harackiewicz, J. M., Barron, K. E., Pintrich, P. R., Elliot, A. J., \& Thrash, T. M. (2002). Revision of achievement goal theory: Necessary and illuminating. Journal of Educational Psychology, 94(3), 638-645.

Harackiewicz, J. M., Durik, A. M., Barron, K. E., LinnenbrinkGarcia, L., \& Tauer, J. M. (2008). The role of achievement goals in the development of interest: Reciprocal relations between achievement goals, interest, and performance. Journal of Educational Psychology, 100(1), 105-122.

Harkin, B., Webb, T. L., Chang, B. P. I., Prestwich, A., Conner, M., Kellar, I., ... Sheeran, P. (2016). Does monitoring goal progress promote goal attainment? A meta-analysis of the experimental evidence. Psychological Bulletin, 142(2), 198-229.

Hoyle, R. H. (1995). Structural equation modeling. Thousand Oaks (CA): SAGE Publications.

Hu, L., \& Bentler, P. M. (1999). Cutoff criteria for fit indexes in covariance structure analysis: Conventional criteria versus new alternatives. Structural Equation Modeling: A Multidisciplinary Journal, 6(1), 1-55.

Hulleman, C. S., Schrager, S. M., Bodmann, S. M., \& Harackiewicz, J. M. (2010). A meta-analytic review of achievement goal measures: Different labels for the same constructs or different constructs with similar labels? Psychological Bulletin, 136(3), 422-449.

Koestner, R., Lekes, N., Powers, T. A., \& Chicoine, E. (2002). Attaining personal goals: Self-concordance plus implementation intentions equals success. Journal of Personality and Social Psychology, 83(1), 231-244.

Koestner, R., Otis, N., Powers, T. A., Pelletier, L., \& Gagnon, H. (2008). Autonomous Motivation, Controlled Motivation, and Goal Progress. Journal of Personality, 76(5), 1201-1230.

Lauermann, F., Tsai, Y.-M., \& Eccles, J. S. (2017). Math-related career aspirations and choices within Eccles et al.'s expectancyvalue theory of achievement-related behaviors. Developmental Psychology, 53(8), 1540-1559.

Liem, A. D., Lau, S., \& Nie, Y. (2008). The role of self-efficacy, task value, and achievement goals in predicting learning strategies, task disengagement, peer relationship, and achievement outcome. Contemporary Educational Psychology, $33(4), 486-512$.

Maehr, M. L., \& Nicholls, J. G. (1980). Culture and achievement motivation: A second look. In N. Warren (Ed.), Studies in crosscultural psychology (Vol. 3, pp. 221-267). New York, NY: Academic Press.

Michou, A., Vansteenkiste, M., Mouratidis, A., \& Lens, W. (2014). Enriching the hierarchical model of achievement motivation: Autonomous and controlling reasons underlying achievement goals. British Journal of Educational Psychology, 84(4), 650 666.

Milyavskaya, M., Galla, B., Inzlicht, M., \& Duckworth, A. L. (2018). More effort, less fatigue: How interest increases effort and reduces mental fatigue. PsyArXiv.

Milyavskaya, M., \& Inzlicht, M. (2017). What's So Great About Self-Control? Examining the Importance of Effortful SelfControl and Temptation in Predicting Real-Life Depletion and Goal Attainment. Social Psychological and Personality Science, $8(6), 603-611$.
Milyavskaya, M., \& Inzlicht, M. (2018). Attentional and motivational mechanisms of self-control. In Routledge International Handbooks. The Routledge international handbook of self-control in health and well-being. (pp. 11-23). New York, NY, US: Routledge/Taylor \& Francis Group.

Milyavskaya, M., Inzlicht, M., Hope, N., \& Koestner, R. (2015). Saying "no" to temptation: Want-to motivation improves selfregulation by reducing temptation rather than by increasing selfcontrol. Journal of Personality and Social Psychology, 109(4), 677-693.

Murayama, K., Elliot, A. J., \& Yamagata, S. (2011). Separation of performance-approach and performance-avoidance achievement goals: A broader analysis. Journal of Educational Psychology, 103(1), 238-256.

Nicholls, J. G. (1984). Achievement motivation: Conceptions of ability, subjective experience, task choice, and performance. Psychological Review, 91(3), 328-346.

Nunnelly, J. C., \& Bernstein, I. H. (1994). Psychometric theory (3rd ed.). NewYork: McGraw-Hill.

Peetz, J., Milyavskaya, M., \& Davydenko, M. (2020). When Time on Task Is Seen as a Reward: Autonomous Motivation Increases Preference for Pursuing Goals More Often for Less Time. Collabra: $\quad$ Psychology, $\quad 6(1), \quad 13$ https://doi.org/10.1525/collabra.285

Perez, T., Cromley, J. G., \& Kaplan, A. (2014). The role of identity development, values, and costs in college STEM retention. Journal of Educational Psychology, 106(1), 315-329.

Perez, T., Dai, T., Kaplan, A., Cromley, J. G., Brooks, W. D., White, A. C., ... Balsai, M. J. (2019). Interrelations among expectancies, task values, and perceived costs in undergraduate biology achievement. Learning and Individual Differences, 72, 26-38.

Pintrich, P. R., \& de Groot, E. V. (1990). Motivational and selfregulated learning components of classroom academic performance. Journal of Educational Psychology, 82(1), 33-40.

Pintrich, P. R., Smith, D. A. F., Garcia, T., \& Mckeachie, W. J. (1993). Reliability and Predictive Validity of the Motivated Strategies for Learning Questionnaire (Mslq). Educational and Psychological Measurement, 53(3), 801-813.

Plante, I., O'Keefe, P. A., \& Théorêt, M. (2013). The relation between achievement goal and expectancy-value theories in predicting achievement-related outcomes: A test of four theoretical conceptions. Motivation and Emotion, 37(1), 65-78.

R Core Team. (2019). R: A language and environment for statistical computing (Version 3.6.2). Vienna, Austria. Retrieved from https://www.R-project.org/.

Ratelle, C. F., Guay, F., Vallerand, R. J., Larose, S., \& Senécal, C. (2007). Autonomous, controlled, and amotivated types of academic motivation: A person-oriented analysis. Journal of Educational Psychology, 99(4), 734-746.

Rawsthorne, L. J., \& Elliot, A. J. (1999). Achievement Goals and Intrinsic Motivation: A Meta-Analytic Review. Personality and Social Psychology Review, 3(4), 326-344.

Robinson, K. A., Lee, Y., Bovee, E. A., Perez, T., Walton, S. P., Briedis, D., \& Linnenbrink-Garcia, L. (2019). Motivation in transition: Development and roles of expectancy, task values, and costs in early college engineering. Journal of Educational Psychology, 111(6), 1081-1102.

Robinson, K. A., Perez, T., Nuttall, A. K., Roseth, C. J., \& Linnenbrink-Garcia, L. (2018). From science student to scientist: Predictors and outcomes of heterogeneous science identity trajectories in college. Developmental Psychology, 54(10), 1977-1992. 
Rosseel, Y. (2012). lavaan: An R Package for Structural Equation Modeling. Journal of Statistical Software, 48(2).

Ryan, R. M., \& Deci, E. L. (2000). Self-determination theory and the facilitation of intrinsic motivation, social development, and well-being. American Psychologist, 55(1), 68-78.

Ryan, R. M., \& Deci, E. L. (2008). From Ego Depletion to Vitality: Theory and Findings Concerning the Facilitation of Energy Available to the Self. Social and Personality Psychology Compass, 2(2), 702-717.

Senko, C., \& Hulleman, C. S. (2013). The role of goal attainment expectancies in achievement goal pursuit. Journal of Educational Psychology, 105(2), 504-521.

Senko, C., \& Tropiano, K. L. (2016). Comparing three models of achievement goals: Goal orientations, goal standards, and goal complexes. Journal of Educational Psychology, 108(8), 11781192.

Sheldon, K. M., \& Elliot, A. J. (1998). Not all Personal Goals are Personal: Comparing Autonomous and Controlled Reasons for Goals as Predictors of Effort and Attainment. Personality and Social Psychology Bulletin, 24(5), 546-557.

Sheldon, K. M., \& Elliot, A. J. (1999). Goal striving, need satisfaction, and longitudinal well-being: The self-concordance model. Journal of Personality and Social Psychology, 76(3), 482-497.

Simons, J., Dewitte, S., \& Lens, W. (2003). "Don't Do It for Me. Do It for Yourself!" Stressing the Personal Relevance Enhances Motivation in Physical Education. Journal of Sport and Exercise Psychology, 25(2), 145-160.

Sommet, N., \& Elliot, A. J. (2017). Achievement goals, reasons for goal pursuit, and achievement goal complexes as predictors of beneficial outcomes: Is the influence of goals reducible to reasons? Journal of Educational Psychology, 109(8), 11411162.

Stoeber, J., Uphill, M. A., \& Hotham, S. (2009). Predicting Race Performance in Triathlon: The Role of Perfectionism, Achievement Goals, and Personal Goal Setting. Journal of Sport and Exercise Psychology, 31(2), 211-245.

Tabachnick, B. G., \& Fidell, L. S. (2007). Using multivariate statistics, 5th Ed. Needham Height, MA: Allyn \& Bacon.

Tulis, M., \& Fulmer, S. M. (2013). Students' motivational and emotional experiences and their relationship to persistence during academic challenge in mathematics and reading. Learning and Individual Differences, 27, 35-46.

Urdan, T., \& Mestas, M. (2006). The goals behind performance goals. Journal of Educational Psychology, 98(2), 354-365.

Vanderstoep, S. W., Pintrich, P. R., \& Fagerlin, A. (1996). Disciplinary Differences in Self-Regulated Learning in College Students. Contemporary Educational Psychology, 21(4), 345362 .
Vansteenkiste, M., Lens, W., \& Deci, E. L. (2006). Intrinsic Versus Extrinsic Goal Contents in Self-Determination Theory: Another Look at the Quality of Academic Motivation. Educational Psychologist, 41(1), 19-31.

Vansteenkiste, M., Lens, W., Elliot, A. J., Soenens, B., \& Mouratidis, A. (2014). Moving the Achievement Goal Approach One Step Forward: Toward a Systematic Examination of the Autonomous and Controlled Reasons Underlying Achievement Goals. Educational Psychologist, 49(3), 153-174.

Vansteenkiste, M., Sierens, E., Soenens, B., Luyckx, K., \& Lens, W. (2009). Motivational profiles from a self-determination perspective: The quality of motivation matters. Journal of Educational Psychology, 101(3), 671-688.

Vansteenkiste, M., Simons, J., Lens, W., Sheldon, K. M., \& Deci, E. L. (2004). Motivating Learning, Performance, and Persistence: The Synergistic Effects of Intrinsic Goal Contents and Autonomy-Supportive Contexts. Journal of Personality and Social Psychology, 87(2), 246-260.

Vasalampi, K., Nurmi, J.-E., Jokisaari, M., \& Salmela-Aro, K. (2012). The role of goal-related autonomous motivation, effort and progress in the transition to university. European Journal of Psychology of Education, 27(4), 591-604.

Vrugt, A., \& Oort, F. J. (2008). Metacognition, achievement goals, study strategies and academic achievement: Pathways to achievement. Metacognition and Learning, 3(2), 123-146.

Wang, M.-T., Degol, J., \& Ye, F. (2015). Math achievement is important, but task values are critical, too: Examining the intellectual and motivational factors leading to gender disparities in STEM careers. Frontiers in Psychology, 6.

Werner, K. M., Milyavskaya, M., Foxen-Craft, E., \& Koestner, R. (2016). Some goals just feel easier: Self-concordance leads to goal progress through subjective ease, not effort. Personality and Individual Differences, 96, 237-242.

Werner, K. M., Milyavskaya, M., \& Koestner, R. (2018). Examining the role of approach-avoidance and autonomouscontrolled motivation in predicting goal progress over time. PsyArXiv.

Wigfield, A., \& Eccles, J. S. (1992). The development of achievement task values: A theoretical analysis. Developmental Review, 12(3), 265-310.

Wu, F., \& Fan, W. (2017). Academic procrastination in linking motivation and achievement-related behaviours: A perspective of expectancy-value theory. Educational Psychology, 37(6), 695-711.

This pre-print was designed by KMW using the following template. Should you notice any differences between this file and the version of record, please cite the original published version when available. Template: Wiernik, B. M. (2019, October 11). Preprint templates. https://doi.org/10.17605/OSF.IO/HSV6A 